\title{
Acercamiento psicológico de Franz Kafka a través de su vida y obra
}

\author{
Psychological Approach to Franz Kafka Trough his Life and Work
}

\section{Abordagem psicológica de Franz Kafka através de sua vida e obra}

Eduardo de la Fuente Rocha

Universidad Autónoma Metropolitana, México

edelafuente83@yahoo.com.mx

\section{Resumen}

Un ambiente de ausencias, muertes y desatenciones fueron el crisol donde Kafka gestó una desazón psíquica interna constante, que oscilaba entre su miedo a morir y su rechazo a vivir, en un ambiente que percibía limitante, impositivo, autoritario y despótico, carente de orientación y cariño. Tal percepción de su medio favoreció en el escritor sentimientos de minusvalía y dependencia, sintiéndose unas veces incapaz y despreciable y otras desatento y culpable, lo que lo llevó a aislarse y a autolimitarse, a sentirse invalidado y a evitar el cumplimiento de compromisos y responsabilidades. Sin embargo, a pesar de todo, logró finalmente la aceptación de sí mismo al conciliar las grandes diferencias que habitaban en su mente. Kafka con su obra y su vida invita al lector a lograr un acuerdo psíquico personal para la convivencia diaria con uno mismo.

Palabras clave: angustia de abandono, arte, madre ausente, padre autoritario, psicología. 


\section{Revista Iberoamericana \\ de las Ciencias Sociales y \\ Humanísticas}

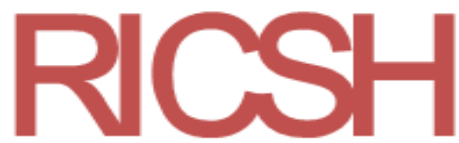

ISSN: 2395 - 7972

\section{Abstract}

An atmosphere of absences, deaths and inattention was the crucible where Kafka created a constant internal psychic distress, which oscillated between his fear of dying and his refusal to live, in an environment that perceived limitation, tax, authoritarian and despotic, lacking orientation and sweetie. Such perception of their environment favored in the writer feelings of disability and dependence feeling, sometimes incapacitated and despicable and other inattentive and guilty, which led to a step and a self limiting, avoiding the fulfillment of duties and responsibilities of the state of disability. However, in spite of everything, he reached, at last, acceptance of himself; and at the same time, he reconciled the great differences that inhabited his mind. Kafka with his work and his life invites the reader to achieve a personal psychic agreement for daily coexistence with oneself.

Keywords: anguish of abandonment, art, absent mother, authoritative father, psychology.

\section{Resumo}

Uma atmosfera de ausências, mortes e desatenção foi o cadinho onde Kafka criou uma constante angústia psíquica interna, que oscilava entre o medo de morrer e a recusa de viver, em um ambiente que percebia limitação, imposto, autoritário e despótico, sem orientação e docinho Tal percepção de seu ambiente favoreceu os sentimentos do escritor de deficiência e dependência, sentindo-se às vezes incapaz e desprezível e outros desatentos e culpados, o que o levou a se isolar e se autolimitar, a se sentir invalidado e a evitar o cumprimento de compromissos e responsabilidades. No entanto, apesar de tudo, ele finalmente alcançou a auto-aceitação, reconciliando as grandes diferenças que habitaram sua mente. Kafka com seu trabalho e sua vida convida o leitor a alcançar um acordo psíquico pessoal para a convivência diária consigo mesmo.

Palavras-chave: angústia de abandono, arte, mãe ausente, pai autoritário, psicologia. 


\section{Revista Iberoamericana \\ de las Ciencias Sociales y \\ Humanísticas}

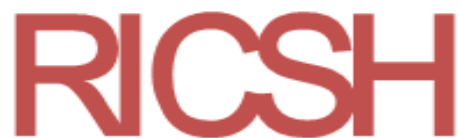

ISSN: $2395-7972$

\section{Introducción}

Para este trabajo se ha elegido a un artista que trató de enfrentar el reto de su propia integración mediante la búsqueda de una expresión articulada y coherente de sí mismo. Específicamente este trabajo se avoca al estudio de la psicología de Franz Kafka, un escritor que nació en la ciudad de Praga en 1882 y murió en Kierling a la edad de 41 años. La vida de este autor partió de experiencias de autoritarismo y sumisión, de abandono y de necesidad de compañía, y luchó, a través de su vida, por tratar de llegar a equilibrar tales extremos. El miedo lo acompañó de la mano, y lo orilló a una ambivalencia de rechazo y contacto con su familia, la sociedad, la mujer, el matrimonio y el trabajo, por lo que huía de cualquier posible relación o compromiso que abriera la puerta de su mundo interior.

Su tarea de autointegración psíquica estuvo entintada por sus deseos de expresión opuestos a su autolimitación, sus sentimientos de minusvalía opuestos a su anhelo no consciente de grandeza, la desatención hacia sí mismo y la gran atención a su trabajo como escritor.

Kafka transitó muchas veces entre el compromiso de ser él mismo y su tendencia apática hacia el trabajo dentro de las instituciones, pero su lucha principal se dio al enfrentar el desmembramiento y la muerte de sí mismo para acudir al llamado psicológico de un acuerdo interno que le permitió la plenitud de vida. Por ello es importante adentrarse en la lucha psicológica que experimentó este autor para llegar a ser Franz Kafka.

La tesis que aquí se desarrolla busca mostrar que las diversas imágenes psicológicas introyectadas en la psique de Franz Kafka pudieron ser articuladas en su mente, lo que permitió la integración de su psique; integración que se expresó socialmente en una aportación creativa. 


\section{Revista Iberoamericana \\ de las Ciencias Sociales y \\ Humanísticas}

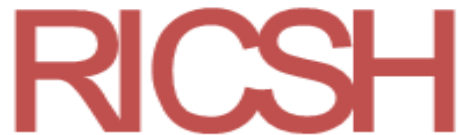

ISSN: 2395 - 7972

\section{Método}

Se utilizó un diseño de investigación cualitativa, específicamente un diseño narrativo biográfico que se sustentó en los datos que sobre la historia de Franz Kafka aportó Reiner Stach. Se buscó desentrañar cuestiones psicológicas que no estaban claras, a partir de un marco teórico psicoanalítico. En suma, se trata de un microanálisis de caso de este artista tomando como base la vida y obra de este artista. El estudio se refiere a una época del mismo escritor que va desde su nacimiento (1883) hasta el momento de su muerte. Se entiende al sujeto de estudio contextualizado. En la investigación se analizó fundamentalmente lo siguiente: La conformación y sustento del desarrollo psíquico y creativo del autor, ello permite una comprensión, desde otra mirada, de su bloqueo con la figura femenina de autoridad y el desarrollo de su sensibilidad sustentada en figuras masculinas, teniendo como eje de la reflexión su aislamiento psíquico en el que se estableció una lucha interna entre sus figuras psicológicas de autoritarismo y sumisión.

\section{Desarrollo}

Hablar de Franz Kafka remite a las puertas de un mundo interior fantástico, peligroso y deshumanizado en el que habitaba el escritor. Sin duda su percepción profunda de la vida ofrece fortaleza a cada lector por medio del reconocimiento de valores humanos a veces ignorados. La historia se remonta al año de 1882 en el que, después de su enlace matrimonial, Hermann Kafka y Julia Löwy se instalaron en Praga, ciudad donde creció su familia. El 3 de julio de 1883 nació su primogénito Franz, quien recibió dicho nombre de pila en honor al emperador Francisco José I. También cabe decir que recibió este nombre para honrar a su abuela materna, llamada Franziska.

El padre de Franz abrió las puertas de un negocio apoyado en la dote que recibió de Julia. Se trataba de un almacén de novedades que no tardó en convertirse en un comercio grande, lo que le permitió a la familia, durante la infancia de Franz, pertenecer a la clase social media alta. Como era usual en las familias de esta clase social, el infante fue atendido por niñeras e institutrices, pues la madre debía atender la caja de la tienda familiar. Por tal motivo, el pequeño solo veía a sus padres a la hora de la comida. Franz experimentó, en sus primeros años, la ausencia de la madre: fue atendido por mujeres que la sustituían en tal función. 


\section{Revista Iberoamericana \\ de las Ciencias Sociales y \\ Humanísticas}

ISSN: $2395-7972$

En 1885 nació el primer hermano de Franz, George Kafka, quien, en diciembre de 1886, murió de sarampión a los 15 meses de edad (no se cuenta con fechas exactas de su nacimiento o de su defunción). El tercer hijo fue Heinrich, quien nació el 27 de septiembre de 1887 y murió de encefalitis el 11 de abril de 1888 (Stach, 2016). Las muertes de sus dos primeros hermanos marcaron significativamente la infancia de Franz: un niño que a los cuatro años de edad había visto de cerca la presencia de la muerte. Quedó afectado al percibir su fragilidad ante la vida, y temeroso de lo que ella le pudiera traer. El pequeño sintió la certeza de muerte al ver que los hermanos pequeños podían aparecer y desaparecer. Lo mismo sucedía con los sirvientes o vecinos a quienes veía cambiar constantemente. Estas vivencias constantes de cambio y pérdida generaban en Franz la sensación de que él también podría desaparecer en cualquier momento.

En sus primeros cinco años de vida, aunado a dichas pérdidas, Franz se sintió abandonado por la madre y golpeado moralmente por el padre. A la madre la percibió ausente y lejana. La sensibilidad de esta, quedó afectada después del fallecimiento de dos de sus hijos. Creía que los niños hubieran podido sobrevivir si ella se hubiera quedado en casa y los hubiera cuidado. Así, la historia de la madre mostró primero una conducta de desapego que derivó en una autoacusación. El distanciamiento quedó, entonces, significado por la madre como culpa por la muerte de sus dos hijos varones y Franz aprendió que el desapego lleva a la culpa. También esta experiencia implicó que considerara a la madre y a la mujer como un elemento que puede poner en riesgo la vida de otro. Lo femenino quedó significado como subordinación y dependencia. Ello llevó a Franz a experimentar por una parte un sentimiento de desprotección que le duró toda la vida y, por otra, un sentimiento de culpa que le sobrevenía cada vez que se aislaba y dejaba sin atención al medio que le rodeaba. La madre también le modeló la dependencia hacia la figura de los hombres sin los cuales era difícil salir por sí misma.

Por otra parte, desde el comienzo, el padre fue quien marcó la pauta de la educación de Franz. Este insistía en el valor del esfuerzo para conseguir objetivos; la madre quedó relegada a un papel secundario en dicho aspecto (Acosta, 1998). Hermann había tenido que ayudar desde los siete años a su propio padre en el negocio familiar haciendo entregas antes de ir al colegio y los viernes antes del sabbat. La cultura del esfuerzo no era en Hermann tan auténtica, ya que, como se mencionó, se había hecho rico con la dote recibida por su boda con Julia, la cual, posiblemente, le compensó de un sentimiento de inferioridad. La 


\section{Revista Iberoamericana \\ de las Ciencias Sociales y \\ Humanísticas}

ISSN: $2395-7972$

personalidad de Hermann se sustentaba en el autoritarismo, en la exigencia y en un ideal exagerado de sí mismo que encubría un sentimiento de inferioridad. Hermann quiso hacer de Franz una extensión de su voluntad. Ante este trato, el hijo solo podía existir si aceptaba ser lo que el papá deseaba que fuera, lo cual implicaba para aquel renunciar a su propia esencia y al reconocimiento de sus particulares potencialidades para convertirse en un ser inferior del que su progenitor podía desconfiar, lo cual alimentaría el sentimiento en el padre de ser superior.

En 1889, Hermann Kafka, más próspero cada día, se instaló con su familia en una hermosa mansión de la Edad Media, y ahí vivieron hasta 1896. En este periodo Franz acudió a una escuela primaria cercana al Mercado de la Carne. En esta etapa, Franz sentía el peso del sometimiento que se ejercía sobre él en su casa. Incluso las criadas ejercían dominio sobre él, en particular de la cocinera "Frantiska", quien lo llevaba todas las mañanas a la escuela; al salir de casa, esta le amenazaba con contar a los maestros lo mal portado que era.

Al salir de casa la cocinera decía que le contaría al maestro lo mal que yo me había portado (...). Más o menos cerca de la entrada a la Fleiischmarktgasse el temor de la amenaza predominaba. Ya era de por sí la escuela un lugar de terror y todavía quería empeorarlo la cocinera (Kafka, 1920, Cartas a Milena Jesenská, en Stach 2016, s/p).

Este trato incrementaba en la infancia de Franz la percepción de que los espacios y las relaciones externos eran amenazantes. Vivía temeroso de todos los adultos que lo rodeaban. Para él las autoridades en general, y los padres en particular, podían rechazarlo en cualquier momento. Ello propició un sentimiento de exclusión y reforzó su miedo a la muerte. El percibirse como una extensión del padre y no como un ser distinto también generó en el niño una angustia de aniquilación.

El 22 de septiembre nació su hermana Gabriele, a quien llamaban Elli (1889-1941). Franz, de seis años, tuvo una relación un tanto distante con ella. Él la describe de la siguiente manera: "Una niña sumamente pesada, cansina, miedosa, descontenta, siempre con sentimiento de culpa, exageradamente humilde, maligna, vaga, comilona, tacaña, yo casi no podía mirarla, ni en modo alguno dirigirle la palabra” (Kafka, 1982, p. 15).

El día 25 de septiembre de 1890 nació su hermana Valerie. Franz contaba con siete años y seguía acudiendo a la misma escuela primaria. Aunque Kafka escribió poco de su 


\section{Revista Iberoamericana \\ de las Ciencias Sociales y \\ Humanísticas}

ISSN: $2395-7972$

relación con ella, dio a notar que Valli no fue tan temerosa del padre como lo fueron Franz y Elli. El autor describe la relación que ella tenía con su padre diciendo: "La más feliz en su relación contigo era Valli. Siendo la más próxima a su madre, se adaptaba a ti de un modo parecido a ella, sin mucho esfuerzo ni daño" (Kafka, 1982, pp. 14-15). Franz muestra, a través de esta afirmación, la despersonalización que se operó en Valli, convirtiéndose en una extensión de la madre.

La más pequeña de las hermanas de Franz fue Ottilie, quien nació el 29 de octubre de 1892, a la que cariñosamente Franz llama Ottla. Fue una cómplice en su relación con el padre. En Carta al padre relata la relación de Ottla y Hermann. En palabras de Franz:

Vosotros dos siempre estabais en posición de combate, siempre de refresco, siempre rebosando energía. Un espectáculo tan grandioso como desolador. En un principio estuvisteis seguramente los dos muy próximos el uno al otro, pues, de nosotros cuatro, Ottla quizás siga siendo hoy la imagen más perfecta del matrimonio entre nuestra madre y tú y de las fuerzas que concurrieron en él (Kafka, 1982, pp. 15-16).

A través de esta afirmación puede suponerse que cuando los padres de Franz ya estaban grandes, la madre se fortaleció y Ottla se identificó con esa madre fuerte. El proceso de Kafka estaba sustentado en el deseo de ser él mismo y no de cumplir con el deseo enajenante de otro sobre él. Tal similitud entre los dos hermanos, convirtió a Ottla en la perfecta cómplice, la confidente y en algunos momentos el soporte anímico del autor.

Los primeros años de Franz Kafka transcurrieron en soledad, dada la marcada diferencia de edades entre él y sus hermanas. Las constantes mudanzas tanto del local comercial de los padres como de la vivienda familiar y la rotación del personal de la casa son una muestra de que la familia estaba siempre en búsqueda de una mejoría material y social, lo que era resultado del deseo del padre de colocarse cada vez más dentro de la burguesía. La falta de aceptación del padre de su propio nivel, actuada en estos movimientos, modeló en Kafka sentimientos de minusvalía y falta de estabilidad. Este desequilibrio hizo que se sintiera solo y, por lo tanto, vulnerable frente al padre y a su fuerza. Ello forjó la relación negativa entre ambos e influyó en el carácter del pequeño Franz. En palabras de Kafka: "Como padre has sido demasiado fuerte para mí, sobre todo porque mis hermanos murieron pequeños, las hermanas llegaron mucho después, y yo tuve 


\section{Revista Iberoamericana \\ de las Ciencias Sociales y \\ Humanísticas}

ISSN: $2395-7972$

que resistir completamente solo el primer embate y fui demasiado débil para ello" (Kafka, 1982, p. 3).

Kafka internalizó las inseguridades del padre, quien lo hizo sentirse insuficiente. Ello generó en el ánimo de Franz una angustia de muerte, manifestada en un sentimiento profundo de soledad y aislamiento para enfrentar las situaciones agresivas. Percibía al exterior como un espacio peligroso, lo que lo llevó al aislamiento y a la dificultad para expresarse. El no tomar en cuenta a los otros lo asemejó a su madre y por tanto a la desatención. Franz desarrolló a través de estas identificaciones sus propios sentimientos de inadecuación y culpa. Por otra parte, el modelo materno quedó significado para Kafka como el de un ser peligroso que puede llevar a un sujeto a la muerte, por lo que cada vez que Franz quería acercarse a una mujer se sentía amenazado y se alejaba.

En septiembre de 1893 por instancias de su padre, Franz inició estudios secundarios en el Instituto Alemán de la Ciudad Vieja: Staatsgymnasium. "Se empeñó [su papá] en educarlos en alemán, puesto que los egresados del Instituto Alemán de Humanidades jamás tenían problemas: para ellos siempre había cabida en la enorme burocracia austriaca" (Flores, 1998, p. 10). Este empeño fue la expresión de una actitud clasista e interesada que muestra su ansia por pertenecer a la alta sociedad. Al Instituto asistían los hijos de la burguesía judía. Entre los compañeros del Instituto, encontró amigos que lo acompañarían toda su vida, como Oskar Pollak, Ewald Félix Pribram y Hugo Bergmann, quien llegó a ser rector de la Universidad de Jerusalén. Uno de sus compañeros, citado por De Francisco (2019), le recordaba así:

Si me piden que cuente algo característico de Kafka, diría que en él nada llamaba la atención. Siempre llevaba ropa limpia, cuidada, discreta y de buena calidad, pero nunca elegante (...). Todos le teníamos gran afecto y lo estimábamos, pero jamás llegamos a intimar con él; parecía estar siempre rodeado por una mampara de cristal. Ante su sonrisa tranquila y amable, el mundo se le abría ampliamente, pero él se encerraba dentro de sí (cap. 2, sección I, párr. 4).

En 1896 la familia se trasladó a la Zeltnergasse y el 13 de junio de ese año tuvo lugar el Bar Mitzvah de Kafka. Esta ceremonia, de un gran peso en la vida de un hombre judío, marca el final de la infancia y supone la madurez personal del individuo; para Franz esta ceremonia solo significó el aprobar un examen de memoria tedioso presentado ante 


\section{Revista Iberoamericana \\ de las Ciencias Sociales y \\ Humanísticas}

ISSN: 2395 - 7972

mucha gente. En esta experiencia, Franz no podía comprender el sentido del rito pues implicaba la aceptación de su propia madurez. Por otra parte, el modelo impositivo, autoritario y agresivo del padre había sido rechazado por Kafka. Franz no tenía confianza ni fe en su padre y tampoco aceptaba las motivaciones de este que lo llevaban a determinadas formas de educación. Sin embargo, en este periodo de su vida se sometió a la agresión del padre y más tarde utilizó la historia de su sometimiento y falta de respeto hacia su persona como arma para agredir a Hermann.

En 1901 pasó Kafka el Abitur, examen al final de los estudios secundarios. "Él describe este examen como una rutina —ni chispa de interés_-” (Stach, 2016, p. 249), lo cual deja en claro su desprecio e indiferencia hacia la escuela. Esta institución psicológicamente es una figura que se asocia a la madre por su capacidad de protección, contención y cobijo. La escuela es una figura desplazada del símbolo materno. La madre de Kafka no fue una madre contenedora; no lo protegió, se alió con el padre y permitió la agresión de este hacia su hijo. Ello cultivó en el ánimo de Franz desprecio e indiferencia hacia este símbolo, por lo que, al entrar en contacto con la escuela, proyectó en ella tales sentimientos. Franz había generado la conciencia de que el sujeto que muestra indiferencia ante sus deberes resulta culpable. Por ello, al haber culpado a la madre por su distanciamiento lo fue él por su indiferencia a la escuela. Kafka lo relata así:

En nuestro país, los estudiantes de bachillerato judíos tienen muchas veces sus rarezas, se dan entre ellos las cosas más inverosímiles, pero esa fría indiferencia mía, encubierta apenas, indestructible, puerilmente desvalida, llevada hasta extremos ridículos, animálicamente satisfecha de sí misma, y en un niño con una imaginación autosuficiente pero fría, no la he vuelto a encontrar en parte alguna, aunque en mi caso personal eso haya sido la única protección contra el desgaste nervioso que produce el miedo y el sentimiento de culpa (Kafka, 1982, p. 21).

El haberse sentido insuficiente ante las expectativas de los otros le generaba culpa. Kafka encubrió sus miedos y su sentimiento de culpa con la indiferencia, con lo que generaba un círculo vicioso que crecía cada día. Mientras más culpaba a la madre más tenía que protegerse con indiferencia. Se culpaba porque no le importaban los estudios y al mismo tiempo culpaba a las personas a las que él no les había importado. 


\section{Revista Iberoamericana \\ de las Ciencias Sociales y \\ Humanísticas}

ISSN: $2395-7972$

Tras haber intentado estudiar química durante quince días, acabó matriculándose en derecho en la Universidad de Praga (Deutsche Universität). Realizó estudios de historia del arte y de filosofía durante el semestre de invierno. Sin embargo, no pasó mucho tiempo antes de que regresara a la carrera de derecho. Lo anterior se relaciona con el hecho de que su atención estaba centrada en la culpa de no cumplir con las expectativas que los demás tenían de él, y no en sus propios deseos. El no saber exactamente lo que quería implica en este momento de la vida de Kafka una desorientación y al mismo tiempo una necesidad: la de verse a sí mismo fuera del deseo del otro. Kafka en ese momento quería no querer lo que los otros querían.

En ese mismo año se encontró en Praga con su tío Alfred Löwy, director de los ferrocarriles en Madrid y quiso irse con él a trabajar al extranjero. Sin embargo, su tío lo desanimó y Franz continuó con sus estudios. Este hecho da indicios de la tendencia de Kafka a evadir la presión que sentía de tener que cumplir con una imagen construida por un ideal ajeno.

A los 19 años inició su amistad con Max Brod en una conferencia impartida por este acerca de Schopenhauer (Max fue su primer biógrafo). En 1903 Kafka asistió a unas conferencias filosóficas con algunos discípulos del filósofo Franz Brentano, donde desarrolló dos nuevas amistades: Félix Wetsch y Oskar Baum. El 6 de septiembre anunció a su amigo Pollak que le iba a enviar un fajo de sus manuscritos, con lo que queda patente su deseo de confiar a un amigo la aceptación de sí mismo. Puede observarse que Franz fue capaz de comprometerse afectivamente a largo plazo con sus amigos, pero no con su familia ni con las mujeres. Los amigos fueron la fuente de aceptación que a él mismo le costaba mucho trabajo darse. Fueron los amigos los que acercaron a Franz al encuentro de su propio deseo y lo invitaron a que explorara en él.

El escritor vivió la mayor parte de su vida en una zona no mayor de ocho kilómetros cuadrados, de la que solamente se apartó para hacer cortos viajes al norte de Italia, a Budapest, París, Viena y Berlín, o a los sanatorios suizos en los que se hospitalizaba por temporadas para el tratamiento de su tuberculosis. Sin embargo, Kafka amaba su pueblo natal, tenía un amor nostálgico por las calles y plazas que transitaba a diario y sentía un vínculo estrecho hacia Praga, ciudad en la que pasó su juventud. De Francisco (2019) cita la descripción que realiza Kafka sobre esta ciudad checa: 


\section{Revista Iberoamericana \\ de las Ciencias Sociales y \\ Humanísticas}

ISSN: $2395-7972$

La ciudad se asemeja al sol. En su núcleo, todo es luz concentrada con intensidad. La luz enceguece, extravía, impide que se encuentren las calles, las casas. Una vez que se ha entrado en su centro, no es posible salir de allí. En otro anillo, más grande que el anterior, se experimenta todavía cierta estrechez, pero la luz ya no irradia sin interrupción; hay oscuras callejuelas, pasadizos escondidos, incluso pequeños lugares que permanecen crepusculares y frescos. Se halla luego un anillo mucho más grande en donde la luz es tan dispersa que es preciso buscarla. Se encuentran en esta zona grandes superficies urbanas de aspecto frío y gris. Más allá, la ciudad linda con el campo abierto, descolorido, otoñal, desnudo, apenas surcado alguna vez por una especie de relámpago (cap. 1, sección II, párr. 2).

La metáfora de Praga muestra una proyección psicológica de sí mismo, asociada al deseo de estar en su propio centro y no querer salir de él, viendo que lo que está a su alrededor distante, es cada vez más frío y gris conforme se aleja del propio centro. Para Kafka, Praga era un vientre materno de protección. Al revisar el significado que daba Kafka a la escuela, se entendió que esta era como una madre que le provocó desprecio e indiferencia. Él hubiera querido contar con la protección de la madre ante la violencia moral del padre y sentirse contenido en un vientre. Ahora aparecía, gracias a la influencia de sus amigos, una nueva percepción del centro de sí mismo y del espacio que lo rodeaba. Sin embargo, su deseo de ser protegido y contenido por lo materno lo encerraba. La vida, representada por el campo, quedaba lejana; para llegar a ella tendría que transitar por lo desconocido y esto mismo, este tránsito, él no se lo permitía. Al observar que Kafka en varias ocasiones salió de la ciudad para visitar otros países o para hospitalizarse surge la duda de si estos hechos no contradecían su deseo de encierro. Sin embargo, puede observarse que tales viajes fueron cortos, e iba acompañado por los amigos que le daban seguridad y alguna vez incluso fue acompañado por su padre. Ello le permitió enfrentar su miedo a cruzar los espacios exteriores. Los hospitales eran metafóricamente centros de atención y prevención que cuidaban de su vida, los cuales podría representar un desplazamiento de la figura de la madre.

En 1904, a los 21 años, comenzó a escribir "Descripción de una lucha", obra que muestra un debate en la psique del autor, que buscaba asegurar su vida ante la lucha entre lo que probablemente es y lo que no es, gestada por la invasión de su fantasía sobre los hechos 


\section{Revista Iberoamericana \\ de las Ciencias Sociales y \\ Humanísticas}

ISSN: $2395-7972$

reales. La lucha interna la generaba su fantasía, la que hacía a un lado lo que verdaderamente pasaba. Sus sentimientos de minusvalía los trataba de compensar con la fantasía. Las cartas que escribe en esta época a Brod y a Pollak delatan un agudo sentimiento de inferioridad. Parece que a finales de este año terminó de redactar la primera versión de este texto, mismo que fue publicado de manera póstuma. En ese período trataba de librarse de los sentimientos de minusvalía introyectados en él desde su infancia.

En el mes de julio de 1905, se dirigió a un sanatorio de Zuckmantel en Silesia y estuvo allí durante varias semanas para reponerse. Volvió a él en el verano siguiente. Su estado de salud dejaba bastante que desear en esta época. Se quejaba, en diferentes cartas, de dolor de cabeza, de dificultades respiratorias, del estómago, de debilidad general, de hipocondría y de otros diversos achaques. Durante su estancia en este sanatorio tuvo una aventura amorosa a la que se referirá ocho años más tarde en una carta a Felice Bauer: “Amar hasta el punto de que mi entraña se viera sacudida hasta lo más hondo, tal vez he amado sólo a una mujer, de esto hará siete u ocho años" (Kafka, comunicación epistolar, 18 de mayo de 1913; citado en Stach, 2016). En este período trataba de cuidar de su salud y explorar sus afectos, buscando un acercamiento al significado y a la presencia de lo femenino.

Mientras exploraba con su sexualidad y su cuerpo, también la vida profesional del autor iba progresando; en noviembre de ese año Franz tomó el primer examen del doctorado, el Rigorosum. Kafka lo superó por tres votos de cuatro. En marzo y en junio de 1906, cuando Franz tenía 23 años, presentó el segundo y el tercer examen del doctorado en leyes, en la Universidad de Praga, con Alfred Weber. Trabajó de abril a octubre con su tío Richard Löwy, abogado de Praga, como "redactor", para emplear su tiempo porque nunca tuvo intención de litigar. En octubre comenzó el año de pasante obligatorio para los juristas en tribunales.

En 1907 escribió "Preparativos para una boda en el campo", en el que acepta dar prioridad a la realidad sobre la fantasía y a lo posible sobre lo improbable representando el proceso de tal decisión en una boda que obliga al protagonista a aceptar una vida social y adaptarse a ella, lo cual lo percibe como una forma de vida agobiante. La boda a la que psicológicamente hace referencia sucede dentro de la propia mente de Franz, en la que tiene que establecer un acuerdo entre su vida interior llena de fantasía y la vida social que la cotidianidad le demanda pero cuya aceptación le resulta insoportable. Algunos de los textos 


\section{Revista Iberoamericana \\ de las Ciencias Sociales y \\ Humanísticas}

ISSN: $2395-7972$

de Kafka que se conservan datan de ese año, en el que estudió francés, inglés y español; más tarde, por razones profesionales, también estudió italiano.

El 1 de octubre de 1907, por recomendación de un vicecónsul de Estados Unidos en Madrid, comenzó a trabajar en Praga en las Assicurazioni Generali, dentro de la sección de seguros de vida. El escritor nunca soportó este empleo, no le apasionaba, lo aceptaba para ocupar su tiempo y trataba de buscar otro trabajo mientras continuaba escribiendo en sus ratos libres. Se sentía presionado socialmente porque tenía que ser económicamente autosuficiente. Aceptar este trabajo era para Franz equivalente a dejar de vivir. Padecía el tener que incorporarse al trabajo porque sus intereses eran los contrarios. Llama la atención que Kafka expresaba su deseo de haber muerto en la plenitud de su vida y en esta institución se dedicaba a vender seguros de vida. Parece ser que la paradoja tanto en la institución como en Kafka consistía en el hecho de que al morir se gana.

El origen de su resistencia a incorporarse a un trabajo se generó en su infancia, cuando rechazaba la posibilidad de tener algún día que someterse a trabajar para el padre. Ahora esta figura se desplazó a la institución laboral. El rechazo hacia las figuras de autoridad y al compromiso social lo experimentó primero en la relación con su padre y luego con las instituciones laborales.

En marzo de 1908 apareció en la revista de Hyperion de Múnich la primera publicación de Kafka; se trataba de ocho piezas cortas publicadas bajo el título de Betrachtung. En este año frecuentó cabarés y tuvo breves aventuras amorosas. En julio dejó las Assicurazioni Generali, alegando que su sensibilidad no podría soportar los insultos con los que se trataban a otras personas dentro de la compañía.

Cuando me marché, la explicación que le di al director — sin que fuese verdad pero tampoco completamente mentira - fue que yo no podía soportar aquellos insultos, que por lo demás nunca iban dirigidos a mí; yo tenía una sensibilidad a flor de piel, por mi experiencia familiar (Kafka, 1982, p. 13).

Las palabras de Kafka muestran que veía a las figuras de autoridad como representantes del desprecio y del sometimiento, proyectando en esas escenas su propia percepción. Cabe observar que las agresiones verbales que presenció en la compañía de las Assicurazioni Generali removían en Franz los recuerdos del padre gritando a los empleados. Según Kafka, su padre consideraba a los empleados como "enemigos pagados" (Kafka, 1982, p. 13) y desconfiaba de ellos. La agresión al trabajador y al subordinado 


\section{Revista Iberoamericana \\ de las Ciencias Sociales y \\ Humanísticas}

ISSN: $2395-7972$

quedó significada en el propio Franz como un signo de desconfianza. Kafka no podría confiar en sí mismo porque el trato de su padre, como un ser inferior a él, le había inoculado desconfianza.

Posteriormente se empleó como abogado de la Compañía de Seguros de Accidentes de Trabajo de Praga, donde llegó a ser muy apreciado. En esta compañía se pensionó por enfermedad dos años antes de su muerte. Viajó en septiembre a Bohemia del Norte por asuntos profesionales.

En 1909, a los 26 años, apareció un artículo suyo sobre una novela de Franz Blei en una revista de teatro llamada Der neue Weg. También en Hyperion se publicaron pasajes de algunas obras suyas. En esta época conoció a diversos personajes, tales como Werfel, Blei, Buber y Hass. Al finalizar ese año realizó un nuevo viaje profesional a Bohemia occidental. Es interesante observar cómo, a medida que pasaba el tiempo, él se fue relacionando con un mayor número de varones y viajó, lo que le amplió su campo de exploración en la vida.

En 1910 comenzó a llevar su diario. En este año se acentuó su tendencia a la introversión y a la meditación solitaria; publicó en la revista Bohemia artículos y relatos; asistió en Praga a una representación de teatro yiddish. En este año tomó unas vacaciones en Saaz, Bohemia, y después viajó a París con Felix Weltsch, Max y Otto Brod. Se cree que una indisposición le obligó a regresar precipitadamente a Praga; la enfermedad lo mantuvo sin trabajar desde de octubre hasta diciembre. En ese mismo año su hermana Elli se casó con Karl Hermann.

En 1911, a los 28 años de edad, viajó con Max Brod por diversos países de Europa escribiendo su diario sobre el viaje. Posteriormente, en septiembre, pasó una semana en un sanatorio cerca de Zúrich. Se encontró con R. Steiner, con el poeta Tucholsky y con el pintor Kubin. Se interesó apasionadamente por el teatro yiddish y entabló relaciones amistosas con el actor Yitzchak Lowy. Continuó escribiendo, reemprendiendo con fervor la escritura de su diario; sin embargo, en este periodo se intensificaron sus insomnios, y las obsesiones por su salud, aumentando la desconfianza en sí mismo. Estos dos síntomas muestran un rasgo obsesivo en su personalidad con su miedo al presente y con su angustia de muerte.

En febrero de 1912 trabajó en la fábrica de un cuñado, en la que tenía intereses su padre, pero dicho trabajo le resultaba aún más insoportable que el anterior, puesto que ocupaba las tardes del escritor, le dejaba muy poco tiempo para escribir y, por lo tanto, lo 


\section{Revista Iberoamericana \\ de las Ciencias Sociales y \\ Humanísticas}

ISSN: $2395-7972$

hacía muy infeliz. En su diario relata lo siguiente: "8 de marzo. Anteayer me hicieron reproches a causa de la fábrica. Luego, una hora en el canapé reflexionando sobre tirarsepor-la ventana" (Kafka, 1912, p. 181). Franz no tenía tolerancia a las indicaciones sobre lo que hacía de manera inadecuada y reaccionaba con violencia orientada hacia sí mismo.

En este año viajó con Brod a Leipzig, donde el editor Rowohlt insistió en que escribiera un libro. Redactó "Veredicto" y publicó un pasaje de su diario en Herderblätter. En "Veredicto", Kafka muestra tres personajes de su mundo psíquico interno: El padre, figura autoritaria y descalificadora; el hijo Georg, que se propone como el sujeto que ha tratado de ser ante su padre una persona socialmente adecuada, y el amigo de San Petersburgo, que es el deseo del padre de que el hijo sea un ser borroso y poco triunfador. Al confrontarse el hijo a los deseos del padre para que este lo reconozca, obtiene un resultado contrario y con ello una condena a ser destruido. Por más que Kafka trate de ser el ideal que se espera de él nunca será tal, pues siempre será reconocida y antepuesta la imagen preferida del mediocre que es a la que llega cada vez que trata de alcanzar ese objetivo. Por tanto, solo queda un camino, el de matar al que ha vivido para cumplir las expectativas del que desea ser ideal. La historia culmina con la muerte del hijo del padre y por tanto con el nacimiento del auténtico autor.

En este año va al sanatorio naturista de Jungborn en el Harz y en este lugar inicia un coqueteo con Margarita Kirchner. Al respecto, es interesante analizar el lugar en el que Franz trata de establecer un acercamiento afectivo con Margarita. Se trata de un sanatorio, lo que hace pensar que cuando está en un lugar que protege su existencia puede acercarse a la mujer. Lo anterior lleva a suponer, como ya se mencionó, que la figura femenina está asociada al peligro de muerte cuando no está en un espacio protegido. Kafka había vivido la experiencia de la desprotección de la madre y de su ausencia. Asimismo, había experimentado la muerte de dos de sus hermanos y sabemos que él mismo vivía angustiado por cesar de existir. La angustia existencial de Kafka era una angustia de muerte asociada a las pérdidas iniciales. La falta de sostenimiento y de seguridad en sí mismo le hacía sentirse inseguro. El hospital simbolizaba un vientre que lo protegía y que contenía su angustia. Estando en él, podía establecer una relación con lo femenino. Cuando no estaba contenido y se sentía agobiado o agredido, dejaba que las ideas suicidas lo invadieran, pues sentía que ellas lo liberaban de la angustia de muerte al imaginar consumarla. 


\section{Revista Iberoamericana \\ de las Ciencias Sociales y \\ Humanísticas}

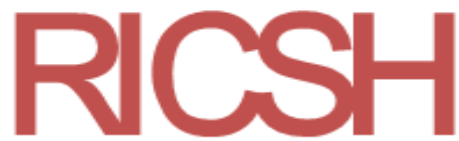

ISSN: $2395-7972$

Durante ese mismo año tuvo encuentros frecuentes con Oskar Pollak en el Hotel Restaurante Stefan para que este revisara sus escritos. De hecho, fue a él a quien le presentó una versión inicial de su famoso escrito La metamorfosis. En este tiempo fue cuando Franz empezó a desilusionarse del judaísmo oriental y difícilmente toleraba a su familia. Al estar viviendo con ellos, constantemente escuchaba el ruido que hacían las visitas y las conversaciones; todo esto lo distraía de su labor de escritura. El rechazo a la familia, al no permitirle estar en contacto consigo mismo, se asociaba a la percepción de no poder ser él a causa de lo que ellos hacían, lo cual activaba en su ánimo en cierta forma su angustia de aniquilación.

En agosto de 1912, Kafka conoció a Felice Bauer en casa de la familia de su amigo Max Brod. La hermana de Max, Sofía, estaba casada con un primo de Felice (Gilman, 2005). En sus diarios, Franz escribió sobre ella. Decía que era como si la conociera de toda la vida y en menos de tres meses le escribió más de un centenar de cartas.

A pesar de su evidente amor por su ciudad, sus viajes eran intentos por liberarse del aislamiento en que se sentía al vivir en Praga. En una carta a Felice, que data de este año relata lo puesto a continuación: “¡Cómo vivo en Praga! Esta ansia de seres humanos que tengo y que se transforma en miedo si se me satisface, sólo en las vacaciones encuentra su estructura adecuada" (Glatzer, 2015, s. p.). Esta cita muestra un paralelismo entre el miedo a enfrentar a su propia familia y a su autoencierro, con el miedo, más que a la ciudad, a establecer relaciones. Esta angustia solo se calmaba saliendo por momentos, pero siempre volvía. Quedarse en contacto consigo mismo también le angustiaba al punto de quererse morir. Huía de sí mismo viajando o muriendo. Tenía dificultades para explorar su mundo inmediato y desarrollarse. La familia para él estaba simbolizada como una forma de agrupación social, realidad que él rechazaba. El agobio y la falta de libertad de la familia estaban reflejados en la Praga de sus orígenes. La libertad de sí la encontraba en el apoyo de sus amigos.

En 1913 asistió, con su director, al Congreso Internacional de Prevención de Accidentes en Viena. También asistió, en esa misma ciudad, a las sesiones del XI Congreso Sionista. Kafka se convirtió en Vicesecretario de la compañía de seguros donde laboraba y fue un año de esterilidad literaria; toda su actividad la absorbió su correspondencia con Felice Bauer. El 16 de junio se encontró con ella en Berlín y le propuso matrimonio en una carta. Ello desencadenó crueles dudas en Franz durante los siguientes meses. 


\section{Revista Iberoamericana \\ de las Ciencias Sociales y \\ Humanísticas}

ISSN: $2395-7972$

El celibato de Franz estaba relacionado con sus rasgos obsesivos. Tras una actividad desbordada de acercamiento que alcanza su clímax en una propuesta de compromiso, le sigue, en lugar de un estado de alegría y de satisfacción por lo que estaba alcanzando, un estado emocional de dudas que atormentan al escritor. Él no estaba plenamente convencido de que el deseo de casarse fuera de él, pero se sentía presionado por la angustia que la alternativa del celibato le producía.

La duda sobre su decisión de mantener su compromiso con Felice se comenzó a disolver al encontrar a una nueva mujer en el Sanatorio Doctor von Hartungen, al que ingresó en septiembre. En este lugar se dio un breve episodio amoroso con Gerti Wasner, una joven suiza de 18 años. A consecuencia de esto, se dio la ruptura de la relación de Franz con Felice. Es interesante observar esta relación triangular generada por Franz en la que decide decirle a la mujer mayor que no pueden continuar su relación porque prefería a la mujer más joven.

Kafka, al hablar sobre el matrimonio, escribía en una cita de Quiroga (s. f.): “La idea de un viaje de luna de miel me llena de horror. Todas las parejas en luna de miel, me ponga o no en su lugar, son un espectáculo repugnante para mí, y cuando quiero darme asco, solo tengo que imaginarme rodeando con mi brazo la cintura de una mujer" (p. 267). Estas expresiones muestran el rechazo de Franz a la mujer.

En el mes de octubre le escribe por primera vez a Greta Bloch, quien era amiga de Felice, con la intención de acercarse nuevamente a Felice. Posteriormente, regresa a vivir con sus padres en la mansión Oppelt. Reinicia su relación con Felice. En diciembre expresa que tanto él como Felice tienen dudas sobre la boda y justifica su deseo de no casarse. Se puede leer en una carta que escribe Kafka a Felice una transcripción de las palabras que esta había expresado en una carta anterior: "Tanto tú como yo tendríamos que renunciar a mucho si nos casáramos, no nos vamos a poner a sopesar para ver de qué lado se inclinaría la balanza. Es sencillamente mucho, tanto por tu parte como por la mía" (Kafka, comunicación epistolar, 29 de diciembre de 1914; citado en Stach, 2016).

Desde inicios de año, las conversaciones con Felice empezaron a ser pausadas. Ambos tenían dudas respecto al matrimonio. Las dudas de Felice se atribuyen a la situación social por la que estaba pasando su familia dado que su hermano "Ferri", quien estaba comprometido con la hija de su jefe, estafó a la compañía para la que trabajaba, por lo cual Felice le compró un pasaje a Estados Unidos para que huyera, mientras que su hermana 


\section{Revista Iberoamericana \\ de las Ciencias Sociales y \\ Humanísticas}

ISSN: 2395 - 7972

Erna esperaba un hijo ilegítimo. Por otro lado, las dudas que se planteaba Franz eran respecto a su carrera, pues pensaba que de no casarse podría dejar Praga e irse a Berlín para dedicarse al periodismo.

Aun con toda la tensión que había entre ellos, Franz viajó a Berlín con su padre y se comprometió con Felice Bauer en Semana Santa. El compromiso se hizo público el 13 de abril y el anuncio se publicó en los periódicos el 21 de abril (Gilman, 2005). Es posible que su padre lo acompañara para ejercer presión sobre él. Sin embargo, a mediados de julio de 1914, nuevamente rompió su compromiso con Felice. En noviembre falleció el padre de esta a consecuencia de una crisis cardiaca, y Kafka se sintió culpable de esa muerte. Nuevamente se manifiesta en él la culpa asociada al rechazo y a la muerte.

En 1914, cuando Kafka tenía 31 años, el escritor Robert Musil, quien recientemente se había convertido en redactor de un suplemento literario para la revista Neue Rundschau, le pidió que le enviara algún escrito, y Kafka le contestó: "Me alegra y me pone triste, pues no tengo nada" (Stach, 2016, p. 1283).

Después de la declaración de la primera Guerra Mundial, su hermana Elli volvió a la casa de sus padres junto con sus hijos. Su otra hermana, Valli, estaba embarazada, por lo que necesitaba ayuda y decidió irse a casa de sus suegros mientras Franz ocupó su apartamento.

En 1914, terminó de escribir En la colonia penitenciaria, obra que podría considerarse una proyección del castigo por la culpa de no haber cumplido con la ley del padre. Kafka hace referencia en este trabajo a un instrumento de tortura que habita en su propia mente y que tiene el propósito de hacer que el preso entienda su propia falta inscrita en lo más profundo de su ser, mediante el dolor y el suplicio. Franz trata entonces de reconocer en sí mismo a partir del suplicio el motivo de su culpa. También trabajó en las obras El proceso, "Recuerdo del ferrocarril de Kalda", "El maestro de la aldea" y "El substituto".

En 1915, Greta Bloch se volvió a acercar a Franz por medio de una carta, con la intención de ayudar a que reanudara su comunicación con Felice. Este acto logró que Franz le escribiera para acordar el encuentro a finales de enero en Bodenbach, una ciudad fronteriza entre Austria y Alemania, Se citaron ahí aunque era difícil el recorrido en tren. Sin embargo, ella acudió acompañada de dos amigas. En mayo, Italia declaró la guerra a Austria-Hungría, y en el verano, a falta de soldados, se llamó a los nacidos entre 1878-1894 


\section{Revista Iberoamericana \\ de las Ciencias Sociales y Humanísticas}

ISSN: 2395 - 7972

a una nueva revisión médica que informaría quiénes eran aptos para ir al campo de batalla. Kafka expresó a Felice sus deseos de servir si su salud se lo permitía. Pasada la revisión médica, le informaron que sí era apto para ir al frente, pero su trabajo no se lo permitió. El Instituto de Seguros solicitó eximir a Kafka y a otro funcionario del deber militar por ser imprescindibles e insustituibles para la empresa.

Felice y Franz se volvieron a ver otras dos veces en el año. En julio pasaron dos días en Karlsbad, después de la decepción que le provocó a Franz no poder servir en el ejército. En 1916, realizó un viaje profesional a Karlsbad. El cierre de fronteras cerró también la vida social y literaria del autor, puesto que tanto su editor Kurt Wolff como su amigo Robert Musil tuvieron que tomar parte en la guerra en Bélgica y Linz, respectivamente. Kafka solicitó a su jefe que se revocara la reclamación de su empresa para que él pudiera servir. En agosto terminó uno de los permisos que la milicia había aprobado para que Franz se mantuviera como civil: lo asignaron a un regimiento, pero fue retirado el mismo día por petición del Instituto de Seguros.

Tuvo otro encuentro con Felice en Marienbad para pasar las vacaciones de verano. Fue la primera vez que se vieron después de un año de distanciamiento. De acuerdo con los diarios de Franz, este fue el más feliz de sus encuentros. Después de esto, la volvió a ver en noviembre en Múnich. Escribió "La lucha", texto al que se le cambia el nombre a "Franziska" debido a que los títulos con asociaciones militares tenían hartos a los lectores. Publica "Un sueño” y escribe “Guardián del sepulcro”. En 1917 se vuelve a comprometer con Felice y meses después se entrevista con ella en Praga y esta vez rompen definitivamente. Este año resulta literariamente muy fecundo para Kafka. Además de los 14 relatos que integran la colección llamada Un médico de aldea, escribe: "El puente", "El cazador Gracchus" y "El vecino".

En el relato de "El puente" lo que permite pasar de un lado al otro es el protagonista, quien sirve de vínculo. Y se encuentra sostenido solamente por sus manos y sus pies. Si se suelta caerá en un profundo abismo. El relato muestra el estado psíquico en el que Kafka se encuentra; permite que otros pasen encima de él, pero cuando se voltea para ver quiénes lo recorren, cae en el abismo. Permitir que algunas formas de ser sociales pasen por encima de él y enfrentarlas lo harían sentir abatido. 


\section{Revista Iberoamericana \\ de las Ciencias Sociales y \\ Humanísticas}

ISSN: $2395-7972$

En el relato "El vecino", Kafka hace referencia a una forma de trabajo rutinario que lo lleva a mantener una situación preestablecida y a no avanzar en su propio desarrollo. Las oportunidades de progreso las transfiere a otro personaje que representa aquellas características a las que teme, que es la propia insuficiencia e incapacidad para lograr por sí mismo las cosas. Este cuento refleja a Kafka tratando de identificarse con las habilidades del padre al mismo tiempo que las rechaza y desconfía de ellas, manteniéndolo en un estado de detención en cuanto a su progreso.

También en 1917 escribió "Una confusión cotidiana", "La verdad sobre Sancho Panza", "El silencio de las sirenas" y "La muralla de China". En este último texto expresa psicológicamente la narración de un viaje al interior de sí mismo para construir los propios límites. Escribió, además, los aforismos reunidos bajo el título de Reflexiones sobre el pecado. También escribió el relato "El sufrimiento". El significado psíquico de esta narración muestra la creencia de un sujeto que considera que para llegar a realizarse como un artista y perfeccionar su trabajo deberá mantenerse aislado. Para Kafka, aislamiento es superación, aunque implica sufrimiento.

Publicó en Berlín, en la revista Marsyas, "Un viejo pergamino", "Un fratricida" y "El nuevo abogado". En este último se puede ver que Kafka se percibe como un sujeto fuerte que sirvió de sustento a un gran hombre y que ha avanzando en la vida paso a paso, y que hoy merece ser recibido en un ámbito y en un tiempo diferente. Pero ahora el camino a seguir es confuso y el espacio disponible es estrecho, lo que genera en él agresión. Al sentirse constreñido por las limitaciones actuales, el protagonista decide aislarse y sumergirse en los textos.

A causa de la tuberculosis pulmonar que siempre padeció, decidió pedir un permiso por tres meses, que se convierten en ocho, para ir a vivir con su hermana Ottla en Zürau, en la finca que ella heredó de la familia de su esposo. En ese mismo año publicó "Chacales y Árabes". En él habla de la percepción de su lucha interior, en la que algunas veces una parte somete y maltrata a otra. La lucha entre estas partes genera unas veces resentimiento y desconfianza mutua y en otras, colaboración. También publicó "Comunicación a una academia" (bajo el título de "Dos historias de animales") en Der Jude, revista dirigida por Martín Buber. 


\section{Revista Iberoamericana \\ de las Ciencias Sociales y \\ Humanísticas}

ISSN: $2395-7972$

En 1918, a los 35 años, Kafka experimentó un nuevo estancamiento respecto a su producción literaria, que se redujo al breve relato titulado "Prometeo", en el cual aborda el dolor que un ser humano recibe como castigo por haberse atrevido a irrumpir en los secretos. Por ello paga primero con el dolor, luego con la confusión de su ser en la materia, después con el olvido de sí mismo y por último con el tedio en la permanencia de la materia. Se trata de una muestra del estado psíquico que lo mantuvo en ese año con una baja producción literaria. Si bien su ritmo de escritura en ese año decayó, se entregó a reflexiones religiosas y metafísicas de las que son testimonio sus diarios íntimos. En enero del año siguiente, con la creciente tensión social contra los germano-parlantes y los judíos en Praga, los padres de Franz decidieron abandonar la tienda; la traspasaron a un pariente de Julie, Bedrich Löwy, e invirtieron en bienes estables.

En el año de 1919, a los 36 años, el único texto importante que escribió fue Carta al padre, que tiempo después sería uno de los textos que permitieron explorar sus interacciones familiares y la difícil relación que el autor tenía con su padre. En este mismo año, conoció en Schelessen a Julie Wohryzek, con quien tuvo un proyecto de matrimonio. Hermann Kafka se opuso a razón del estrato social de la familia de Julie. Aun así, Franz pensaba casarse a inicios de noviembre, pero renunció en ese mismo mes, aunque continuó visitándola hasta julio de 1920.

En 1920, Kafka permaneció en Merano, ciudad al norte de Italia, desde abril hasta junio. En abril inició correspondencia con una nueva mujer llamada Milena Jesenzká. Se encontró con ella en Viena y estuvieron juntos por cuatro días. Durante el segundo semestre de este año, volvió a laborar en la compañía de seguros. Trabajaba muy poco pero encontró comprensión entre sus superiores. A finales de diciembre se internó en el sanatorio de Tatranské Matliare (en los Altos Montes Tatra), donde permaneció por 10 meses. Allí conoció a Robert Klopstock. A los 38 años, empeoró su salud debido a la tuberculosis pulmonar. Por su enfermedad, su producción literaria fue escasa, incluso interrumpió su diario hasta octubre. Regresó a Praga a finales del verano, donde trató de incorporarse a su trabajo. Allí se encontró con Milena, con quien había mantenido una espaciada correspondencia desde abril de 1920 y el día 15 de octubre le confió su diario.

El día 8 de mayo de 1922 tuvo lugar la última visita de Milena a Kafka en Gmünd por un solo día; después de ello, intercambiaron algunas cartas más. Desde finales de junio hasta septiembre vivió con su hermana Ottla en Plana an der Luschmitz; el escritor hacía 


\section{Revista Iberoamericana \\ de las Ciencias Sociales y \\ Humanísticas}

ISSN: $2395-7972$

breves viajes a Praga. En la revista Genius publicó en el otoño "Primer sufrimiento", y en la Neue Rundschau "Un artista del hambre"; en este trabajo, Kafka muestra la visión de sí mismo como artista que construye su propio estado de autovictimización, explicando que en realidad ha quedado reducido al encierro en sí mismo y que así permanecerá hasta morir, debido a que lo que la vida le ofrece, no le agrada. Cabe observar que lo desagradable es la comida, lo que muestra desde la oralidad, el rechazo a lo que la madre primero y después la mujer nutricia le pudieran ofrecer.

En 1923 escribió "Una mujercita y la madriguera". Permaneció en Praga sin salir todo el primer semestre del año. Escribió en julio a Hugo Bergmann diciendo que no se sentía feliz en ese momento de su vida, pero que pronto lo sería (Kafka, comunicación epistolar, s. f. en Stach, 2016). En este mes se traslada con la familia de su hermana Elli a Müritz, en el Báltico.

Cuando Franz tenía 40 años de edad, trabó amistad con Dora Dymant, una joven de 25 años. Ella lo acompañó en sus últimos años de vida. En el peor momento de la inflación en Alemania, se instaló en Berlín con Dora, en la Grumewaldstrasse. Como consecuencia de su estancia en Müritz, donde vivió en contacto con los judíos orientales, perfeccionó sus conocimientos del hebreo y siguió algunos cursos en la escuela superior para el conocimiento del judaísmo. Tuvo deseos de emigrar a Palestina, pero no pudo hacerlo a consecuencia de su salud. En febrero de 1924, a causa de la subida de los alquileres, tuvo que mudarse a la Heidestrasse. El padre de Dora Dyamant se negó a dar el consentimiento para que su hija se casara con un hombre de 41 años.

En el mismo año, Franz escribió "Josefina la cantante" y permitió su publicación para agenciarse algo de dinero. Este relato muestra una crítica hacia la superficialidad de lo que algunos seres manifiestan y quienes son como una rata a la que siguen otros que a su vez son como ratones. El escritor muestra el hartazgo que tiene de la simulación, la cual pudiera en un momento habitarlo y convertirlo en un artista sin contenido y sin verdad.

Su tío Siegfried acudió a visitarle en Berlín y decidió que era necesario internarlo en un sanatorio. Max Brod lo llevó a Praga, de donde, después de pasar unos días con sus familiares, fue trasladado a Wiener Wald en la Baja Austria. El 19 de abril se internó en el sanatorio de Kierling, cerca de la capital de Austria. El día 3 de junio falleció a los 41 años de edad. Le acompañaban en aquel momento Dora Dymant y Robert Klopstock. Fue enterrado, ocho días más tarde, el 11 de julio, en el viejo cementerio judío de Praga. 


\section{Revista Iberoamericana \\ de las Ciencias Sociales y \\ Humanísticas}

ISSN: $2395-7972$

En 1931 falleció el padre de Kafka; la madre falleció en 1934, mientras que sus tres hermanas, así como Milena Jesenzka, permanecieron en campos de concentración en los días de la Segunda Guerra Mundial. Los nazis llevaron a las tres hermanas al gueto de Lodz. De allí llevaron a Ottilie al campo de concentración de Theresienstadt y el 7 de octubre de 1943 al campo de exterminio de Auschwitz, donde murió ese mismo día en las cámaras de gas. Dora Dymant murió en Londres en 1952 y Felice Bauer falleció en 1960.

\section{Reflexiones finales}

Franz Kafka se gestó y vivió sus primeros momentos de vida desatendido por la ausencia de la madre, quien no le brindó el sustento psicológico que su infancia requería para formar una confianza básica que le permitiera crecer; con fortaleza se abrió a las experiencias que la vida le ofrecería. Aunado a la distancia afectiva de la madre, creció investido por el relato de la muerte de sus hermanos, lo que propició en el pequeño una angustia ante la posibilidad de muerte, misma que le acompañó toda su vida. Estas vivencias derivaron tanto en el miedo a morir como a vivir, todo lo cual promovió una mayor angustia que en ocasiones solo se calmaba con la idea de que al morir esta lucha concluiría.

El padre modeló en Franz un rol autoritario que el escritor introyectó aunque le pareciera impositivo, despótico, carente de orientación y cariño. El padre ocultaba tras esta máscara a un hombre herido por un sentimiento de inferioridad, que trataba de compensar ascendiendo entre las clases sociales. Las identificaciones que Franz tomó de su padre estaban imbuidas por el temor a no ser suficiente para los demás y por la imposibilidad de verse a sí mismo; solamente podía ver su imagen a través de los demás. El personaje de Hermann que Kafka narra no corresponde al padre real, sino al que habitaba en sus fantasías. Este solo podía verse como un triunfador en comparación con los otros y ello lo hacía también con la imagen que mentalmente Franz tenía de sí mismo como hijo. Por lo que el personaje fantaseado por Kafka del hijo dependiente y desvalido se sentía despreciable ante la presencia también imaginada de un padre poderoso y cruel. La imagen psíquica que formó de su padre y de la forma como lo trataba generó cada día en Franz un sentimiento creciente de minusvalía que le hizo asimilarse a un escarabajo en proceso de destrucción y de muerte. 


\section{Revista Iberoamericana \\ de las Ciencias Sociales y \\ Humanísticas}

ISSN: $2395-7972$

La imagen de sí, en Kafka, generaba en el escritor diversos miedos que lo orillaban a rechazar y mantener contacto con la familia, con la sociedad, con la mujer, con el matrimonio, con el trabajo y con todas las posibles relaciones y compromisos que le abrieran el espacio de su mundo interior. Para Franz, el rechazo y la desatención estaban significados en su pensamiento como elementos generadores de culpa. Para separarse de estos sentimientos culpígenos se aislaba y con ello gestaba más culpa; así se fortalecía un círculo vicioso en el que estaba atrapado.

El sentimiento de su desvalimiento ante la vida produjo en Kafka una conducta dependiente. Se apoyaba en los demás material y moralmente. Por ello, para poder sentir un poco de seguridad en su trabajo como escritor, tuvo que recurrir a la opinión y al apoyo de sus amigos. Su autodesprecio lo limitó y aisló, y le restó libertad, convivencia, acceso a los bienes materiales; le hizo despreciar los logros que en este aspecto había alcanzado su padre. El resentimiento que expresa hacia él en Carta al padre es una proyección del enojo que tenía hacia sí mismo por el autoritarismo que ejercía sobre su persona, para evitar las responsabilidades de enfrentar sus compromisos. Para ello, fomentaba la idea de ser insuficiente, al tiempo que la rechazaba, lo cual generaba otro acceso de desprecio y autoritarismo en él, del que se volvía a defender arguyendo su invalidez.

A pesar de todos estos elementos adversos, Kafka logró admirablemente una aceptación de ser lo que finalmente era. Si tenía que convertirse en un escarabajo y morir, lo admitió. En esta conducta, paradójicamente, radica su grandeza, pues con su obra enseña al lector a aceptar sus luchas internas, a respetar las grandes diferencias que habitan en nuestra mente, y que, sin llegar a un acuerdo, conviven diariamente. Franz Kafka, con la aceptación total de su propia manera de ser, trasciende las limitaciones humanas y hace de la dialéctica mental una representación exacta que inspira al lector a enfrentar la angustia de lo que cada uno es, y a renunciar y a dejar ir lo que no se es.

Sin lugar a dudas este trabajo abre la posibilidad de nuevas investigaciones. Por ejemplo, indagar otras variables psicológicas que deriven en un bloqueo a la sensibilidad de un artista; las consecuencias de la presencia de figuras autoritarias o sumisas en la infancia, y otras variables que puedan generar formas de aislamiento psíquico. 


\section{Referencias}

Acosta, L. (1998). Introducción. En Kafka, F., El castillo. Mádrid, España: Cátedra.

Bataille, G. (2000). La literatura y el mal. Argentina: El aleph.

De Francisco, A. (2019). El mundo psicológico de Kafka, la juventud. encolombia. Recuperado de https://encolombia.com/libreriadigital/lmedicina/mundokafka/2lajuventud/2/.

Deleuze, G. y Guattari, F. (1978). Kafka. Por una literatura menor. México: Ediciones Era. Flores, A. (1998). Expliquémonos a Kafka. México: Editorial siglo XXI.

Gilman, S. (2005). Franz Kafka. Londres: Publisher.

Glatzer, N. (2015). Los amores de Franz Kafka (trads. Roberto Vivero y Pilar Moure). Barcelona, España: Ediciones del Subsuelo.

Kafka, F. (1982). Carta al padre. Buenos Aires, Argentina: Ediciones LEA.

Kafka, F. (2014). Cartas a Felice. Madrid, España: Nordicalibros.

Quiroga, H. (s. f.). Secretos y misterios de hombres y mujeres de la ciencia, el arte y el deporte. Humberto Quiroga Lavié.

Stach, R. (2016). Kafka. Los primeros años. Los años de las decisiones. Los años del conocimiento. Barcelona, España: Acantilado. 